DOI https://doi.org/10.36059/978-966-397-104-9/52-74

\title{
USE OF OPEN TECHNOLOGIES
}

\section{Kyselov V. B.}

\section{INTRODUCTION}

The presence of modern open technologies and thirty years of experience in the development of complex information systems make CSRP projects feasible and practical. Manufacturing, management, sales, customer service, maintenance, and other customer-oriented, business functions can be performed by appropriate units using software specifically designed for these units.

CSRP software applications can provide and retrieve business-critical information from a central ERP-based system used by other organizational units. Software solutions from IBM, Microsoft, Oracle, SAP, PeopleSoft and other software vendors, based on a modern computing architecture that utilizes powerful Intel multi-core processors, allow you to create integrated flexible infrastructures for the needs of specific enterprises for Business On Demand implementation.

The following is a list, including some manufacturers of modern CRM and CSRP systems:

- Applix Inc. - http://www.applix.com;

- Interact Commerce Corporation - http://www.saleslogix.com;

- Nortel Networks - http://www.nortelnetworks.com;

- Oncontact Software - http://www.oncontact.com;

- ONYX Software - http://www.onyx.com;

- PeopleSoft Inc. - http://www.peoplesoft.com;

- Pivotal Corporation - http://www.pivotal.com;

- Point InformationSystems - http://www.pointinfo.com;

- Remedy Corporation - http://www.remedy.com;

- SAP AG - http://www.sap.com;

- Siebel System, Inc. - http://www.siebel.com;

- Staffware - http://www.staffware.com;

- Software AG - http://www.update - marketing.com;

- Worldtrak Corporation - http://www.worldtrak.com;

- YOUcentric, Inc. - http://www.youcentric.com. 
The dynamics of modern business, the growing supply of markets and the "discernment" of consumers have led the management of companies to understand the need to increase the consumer value of the product at the expense of a significant reduction in non-production costs. In addition, as experience in mathematical modeling of production processes, the real reserve for reducing total costs is the optimal organization of movement of raw materials and components for processing and assembly.

In this regard, traditional logistics and management operations for ordering, delivery, warehousing, production release (inventory management), supplemented by the requirements of technology "Order In Time" and "Kanban" at the heart of the Just In Time methodology.

Production and registration cards of the orders of "Kanban" absolutely accurately stipulate and offer quantity of the ordered completing products on the assembly ladder, the point of the production cycle at which these products are needed and the point of time to which the products should be delivered.

The implementation of the "Just in Time" technology is focused on the following key points: accurate planning of the required volume of inventory; achieving the optimum level of inventories at all production sites; reduction or complete elimination of downtime; reduction in batch size (purchase or production) of products and increased batch maneuverability; reduction of time of transfer, processing, delivery of production; minimizing warehouse space and operations.

When implementing this technology, it is necessary to anticipate the irregularity of deliveries due to the fault of suppliers, the possibility of equipment breakage, changes in staff composition, etc. To do this, the production process includes: detailed inspection and maintenance of machines and equipment; interchangeability of workers - workers must be able to work in several workplaces and perform several production operations; Requirements for Suppliers of Guaranteed Supplies, Requirements for Defective Supplies and Fees; use of simple and clear accounting systems (so-called "kanban cards").

These technologies were developed in the mid 80's and were applied mainly in compact enterprises with a clear technological cycle. Automation of production cycle management on the basis of MRP / ERP systems has filled the technology "Just in time" with new content and allowed to apply it to distributed enterprises of a wide range of activities. The process of 
automated management of complex logistics processes based on mathematical models describing the interaction algorithms of external and internal suppliers, schemes and trajectories of the movement of material values, called Supply Chain Management.

The information systems by which management is performed have become known as SCM systems. Supplies that are "tied" into complex chains should not only increase the cost at the chain nodes, but add real value at each stage of the movement. In this regard, the SCM strategy is bidirectional - it covers both the supply of raw materials and components to the enterprise, and the delivery of the finished product "Just In Time" to the market.

There are seven basic principles of the SCM concept:

- monitor market demand closely and plan based on them;

- observe the spatio-temporal distribution of sales and segment consumers based on the need for goods and services;

- equally target the logistics network to the supplier and the customer;

- strategically plan deliveries;

- to develop strategy of chains of movement of material resources;

- actively use methods of attracting new distribution channels;

- use linear programming, mathematical modeling and information technology to increase forecasting accuracy and develop network delivery schedules and optimal traffic routes.

SCM systems, as well as CRM and CSRP systems, "extend" the standard enterprise ERP system into the external environment, forming, in the aggregate, an expanded ERP II enterprise management system. This integrated system makes it possible to implement the baseline of the SCM strategy: "deliver the right product - at the right place - exactly in time - at low cost - with the right customer service." Technological and software SCM solutions are very diverse, but the most in demand nowadays are complex solutions, built on the principle of open systems for interfacing with the standard ERP-core. For example, consider the following solution implemented by Lowson Software on the IBM System platform.

This solution includes the following specialized modules:

- Supply Chain Planner - SCP;

- Demand Planner - DMP;

- Multi-Site Planner - MSP; 
- Yield Optimizer - YOP;

- Advanced Production Planner - APP.

Some of the modules are embedded because they implement direct-tomany (many-to-many) operations of goods and resources to different user groups.

Microsoft Dynamics NAV Supply Chain Management System (formerly Axapta) is a suite of integrated applications including warehouse management, distribution, manufacturing, automated data acquisition (ADCS), and has pricing and e-commerce. The main characteristics of the solution:

- a comprehensive approach to supply chain management integration of distribution and production units, automated data collection, pricing and e-commerce functionality;

- optimization and improvement of warehouse logistics and all warehouse processes;

- support for discrete production - volume-scheduling and production forecasting, flexible definition of production policy;

- modeling of effective business processes and various parameters of production process;

- increased profitability through cost reduction and effective collaboration with partners, including through the Internet.

Effective supply chain management allows you to increase revenue by maintaining inventory levels at the level you need to meet demand, resulting in increased sales, reducing the need for inventory reductions. This also leads to lower transportation costs, storage of goods, additional labor costs through optimal planning of operating facilities and inventories.

Proper supply management is, first and foremost, a cost savings, which means that you can make additional investments from the turnover of the company itself. SCM systems help to reduce the amount of working capital "frozen" in inventory, while improving the level of service provided.

Supply and demand forecasting and supply chain planning tools provide the really necessary level of inventory, taking into account the cost and effective collaboration with partners, including through the Internet.

Effective supply chain management allows you to increase revenue by maintaining inventory levels at the level you need to meet demand, resulting in increased sales, reducing the need for inventory reductions. 
This also leads to lower transportation costs, storage of goods, additional labor costs through optimal planning of operating facilities and inventories.

Demand forecasting and supply chain planning tools provide the really necessary level of inventory, take into account the availability of slow and fast rotating goods, justify advertising activity, seasonal increase / decrease in demand, calculate optimal delivery times, etc. And finally, they make better use of the assets of manufacturing enterprises, as well as retail and network marketing companies through the optimal planning and placement of goods in the available warehouse and store space.

Globalization and internationalization of the economy, fast-growing business dynamics, fierce competition and the struggle for raw materials have increasingly led to situations where, in times of scarcity, only the right business decision is needed. To do this, the manager needs to analyze the situation, formulate Decision Tree, assess risks, and take responsibility for making and implementing the decision in a very short time.

To do all this using only the "hand" tools or Decision Support System modules built into standard ERP systems was quite difficult, and as a result, the risk of making the wrong decision was high. In this regard, formalized decision-making methods under uncertainty, which are described by fuzzy logic, began to develop, and specialized information systems were created using the theory and methods of artificial intelligence.

\section{Systems of teamwork}

The intensive development of computer and communication technologies opens up fundamentally new opportunities for the construction and development of information systems to solve management problems in large, territorially distributed and virtual organizations.

The development vector shifts towards the creation of Informational Multimedia Networks - IMN. A prerequisite for building such a network is a single technology solution for all applications running on this network, and the use of open standards and specifications - that is, you must make extensive use of open systems technology. These are, first of all, H.120, H.261, H.263 audio and video compression standards, H.320, H.323, H.324 multi-protocol standards, operating on both IP and ISDN networks, as well as widely used today is the H.264 video stream compression standard. 
The ITU-T and ISO / IECMoving Picture Experts Group (MPEG) created the MJPEG standard for compression of a separate graphic image, then MPEG-1 and MPEG-2. These standards were broadband-oriented and were used mainly in digital television and for interactive video applications, without intersecting with video conferencing. But with the start of work on MPEG-4, working groups have joined forces. As a result, the H.264 standard, also known as MPEG-4 Part 10 or AVC (Advanced Video Coding), is now used by most video conferencing equipment (VCS) companies.

Groupware is a generic term for information systems (subsystems) that enable a group of people to implement Joint Actoins. For example, prepare and make decisions, peer-review new ideas, manage business units, processes, projects and staff, create software for computers, write project implementation reports, interact with the external environment (government, social organizations, suppliers, partners, customers, competitors).

Much of Groupware arose from the development of messaging tools (the first such tool was a product called PLATO Group Notes, which appeared in 1976). Such systems, usually implemented in local or distributed networks, form Integrated Collaborative Environments - ICE and are intended not only for collaboration, but also for the acquisition and formation of knowledge. In this case, they are defined by the term "Computer Aided Network Groupware". They can also be seen as an evolving technology that studies the impact of computer and communication technologies on the behavior and performance of a group, as well as the implementation processes of complex software and information systems. This discipline is based on computer science, psychology, sociology, management information systems and more. With the development of this technology, many synonyms for the term "computer networking tools" have emerged.

Commonly used in the literature are the terms "computer-based collaboration", "shared software", "team work software", "technology support for workgroup activity", "collective decision support systems", "collective automated work", "collaborative automated work", "computerassisted communication", "flexible interactive technologies for teamwork", and even an "advanced knowledge workshop". In principle, all this means 
the availability of software and hardware that implements the electronic space in which:

- collecting and processing information necessary for decisionmaking;

- management of teams and production of projects;

- formation and reproduction of knowledge - from finding the necessary sources to discussing results and publishing works.

Shared-use software allows a team of employees to take joint actions to accomplish tasks, use shared data and information, and improve corporate communication decision-making.

The software is classified according to the functions performed:

- to support decision making;

- to ensure the process of using general information and generating knowledge;

- to manage collaborative processes;

- to manage communications.

Doug Engelbart, one of the founders of the theory and methods of teamwork, predicted in the 1960s that computers would be able to expand the boundaries of human intelligence in the near future "due to the complexity of software systems and collaboration based on and beyond using new technologies. " His Augmented Knowledge Workshop worked on some fundamental issues that proved to be very important to understanding the implementation of computer collaboration support systems. These include the Dialog Mapping Ware technique, teleconferences, co-creation of electronic documentation, advanced planning, shared databases, organizing contacts between managers and contractors using multimedia tools. Not without the influence of his ideas, in the 1970s, two of the most widely used components of shared software appeared - email and teleconferencing.

In the 80 's, the basic terms and ideas in the field of computer-based collaboration appeared and came into constant use: collective software, collective decision support systems, computer-based collaboration, teleconferences.

Currently, group support systems and electronic meeting organization systems are considered to be the most important components of decision support and enterprise management systems. 
It is hard to imagine a successful company that does not take advantage of the benefits of modern IT. Such technologies, of course, should include those without which it is impossible to organize effective work - technology and systems of team (group) work. The realities of today's business are that the decision-making paradigm has changed - a system of group and distributed work, where middle-level managers are able to receive and analyze any information they need in their workplace, wherever they may be, allow them to delegate some of the decision-making authority middle management solutions. It follows that to implement this paradigm, it is necessary to develop and implement appropriate elements of the information infrastructure at the corporate level.

The actual practice of companies shows that the IT infrastructure of an enterprise, which by its nature belongs to the security subsystems, has a significant, and in some cases, decisive impact on the activities of the company as a whole, as well as on individual business decisions and operations. In particular, successful or unsuccessful implementation of business decisions directly depends on how fully, qualitatively and timely they are backed by adequate information, which is the result of teamwork and managers, IT specialists, analysts.

The activities to be provided with the relevant IT infrastructure are quite diverse. In the general case, there are:

- managing the activities of a large, geographically distributed or virtual company;

- managing complex projects, some of which are outsourced or subcontracted;

- coordination with suppliers and partners;

- managing the portfolio of investments in OnLine mode, participation in electronic stock exchanges;

- knowledge management and distance learning of company employees;

- remote control and management of equipment and technological processes;

- remote participation in scientific experiments, environmental monitoring with the participation of representatives of different countries;

- formation and provision of services using network technologies conducting interactive interviews, conferences, telemridges, etc. 
What is needed to organize such work? Simply the tools for collecting, processing, analyzing, structuring, archiving information and delivering it to the end user - that is, those standard tools that are part of any medium-sized corporate information system are not enough today. Requires specialized technologies and equipment (Groupware) to form Integrated Collaborative Environments - ICE.

\subsection{Video conferencing}

One of the effective types of teamwork is conferences organized on television channels or carried out on the basis of computer and network technologies.

There are currently many varieties of conferencing systems available, including computer conferences (e-mail meetings), mobile caller meetings, desktops, multimedia, TV and video conferencing.

Video conferencing is a kind of simultaneous connection between a number of participants (subscribers) who can see and hear each other, no matter where they are, provided with the use of appropriate telecommunications. For the organization of videoconferences use modern technology, called - VCS. Videoconferencing Session is a video call in real time. Videoconferencing is used as one of the technologies to reduce the costs of preparation, coordination and adoption of a business decision, reducing organizational, temporary, transportation and other costs in territorially distributed organizations, as well as one of the elements of technology "telemedicine", "distance learning" and "communication power representatives with the people".

Experience in the use of such technologies has shown their effectiveness - according to studies by psychologists, the level of perception of information and trust is increased in the interlocutors, if nonverbal language (gestures, facial expressions, body position) is added when communicating with the interlocutors.

Videoconferencing and ongoing video networks for ongoing monitoring of mission-critical processes are increasingly used in corporate governance, regardless of the company profile and type of business. Such technologies not only save time and resources for organizing and holding eye-to-eye meetings, but also provide previously unavailable opportunities. This is a remote monitoring of previously closed processes, managing such 
processes, conducting distance learning directly during real work without active intervention in it, etc.

Video conferences are usually held in the Videoconference Room, equipped with appropriate computer and multimedia equipment, large monitors (plasma panels) with multi-screen image output, television or Web cameras, an electronic board, telecommunication devices. In this case, specialized software is used to compress and decrypt the information, as well as to secure its transmission over open communication channels or over the Internet.

Various modifications of videoconferencing systems allow to take into account the ergonomics of workplaces of personal subscribers, to create optimal conditions for "subscribers-audiences" taking into account lighting, acoustic environment, convenience of transmission and display of video information.

For the organization of videoconferencing between three or more subscribers the technology of multipoint VCS is used, which can be implemented on a specialized video server (Multipoint Conference Unit MCU) or on firmware terminals of VCS.

During the videoconference, its participants can exchange fax images and electronic copies of documents, jointly view presentations and videos. They can send files of various formats, broadcast telemetry data (video sessions with spacecraft), store static and dynamic fragments, and request and retrieve information from remote databases of these information systems.

Professional video conferencing opportunities to discuss analytical materials, scientific ideas, political discussions, and discuss different cultural and artistic fields, create opportunities for engaging in discussions that could not have been attracted earlier because of their remoteness.

To communicate in video conferencing, the subscriber must have a complete VCS terminal, which typically includes: microphones, camcorders, a large screen, arrangement of information display and sound reproduction, as well as a codec providing encoding/decoding of the stream.

As a codec, a computer with appropriate software or software may be used to adapt the VCS systems to different bandwidths and the quality of the transmitted video, namely: use H.261/H.263 standards, MJPEG, MPEG2, MPEG4. In particular, encoding video information using 
MPEG 2/4 codecs allows you to achieve a higher transmission rate, and encoding using the MJPEG codec allows for greater resistance to interference in the communication channel.

One of the Internet Protocol - IP or Integrated Services Digital Network - ISDN is used to connect the VCS to the data network.

In the course of preparation for participation in videoconferencing, a contact book is usually formed in advance of the VCS system, which contains the contact addresses of potential participants. Once agreed with all participants in the videoconference, the address book is approved and used by the organizer (administrator) of the WCC as a basic document for the identification of participants and their connection. There is an opportunity for both personal and group calls. Once the call is acknowledged, voice and video communications are established automatically.

At the request of the subscriber, a voice-only connection may be made initially, with subsequent video connection. If the VCS is made in Point to Point Mode, the call is transmitted directly to the calling party's workplace, and if the communication is to occur in Multipoint Mode, the call first arrives at the video server, which then calls (notifies) other participants in the video conference. The process of video conferencing consists of the following stages: hardware and software initialization of the VCS; establishing a connection, calling a subscriber (s) or video server; identification of subscribers, registration and approval of additional participants; call or disconnect additional subscribers; duplex audio-visual communication; challenge of remote information resources, exchange of materials, record keeping, preparation and adoption of resolutions, final voting, conclusion of the video conference by the chairman or moderator, agreed with all participants having the decisive vote;

Each videoconference subscriber has equal rights and responsibilities. Within the corporate data network, several video conferences can be held simultaneously with the presence of a powerful video server. The need for full CCTV video recording is generally agreed upon in advance - except in the case of recording videoconferencing with subsequent selective editing for media or for archiving important events. Any participant in a video conference can pre-opt out or terminate its participation directly in its process. These actions are determined solely by the participant and the overall situation of the VC. 
The modern communication technologies used in professional VC systems (Digital Videoconferencing System - DVS) make it possible to use them with virtually any communication channels: analog and digital wire telephone channels; radio channels; radio relay lines; fiber optic channels; dedicated telephone and VPN channels; satellite channels; local and Internet networks; GSM/CDMA/GPRS cellular communication channels and so on.

The main communication parameters under which the use of professional VC systems are possible are shown in Table 1.

You can control some important parameters directly in a VCS session: the number of frames that come per second, the real speed of outgoing and incoming IP packets, all and through the channels individually (data, sound, video), the number of lost or distorted IP processes. packages - all and by channels separately (data, sound, video). You can also control and change the basic parameters of both your own system and the remote subscriber system: communication parameters; settings of input and output devices; parameters for digitization and compression of video, sound and data; user interface settings.

Table 1

Basic communication parameters

\begin{tabular}{|l|l|l|}
\hline № & \multicolumn{1}{|c|}{ Parameter type } & \multicolumn{1}{c|}{ Amount } \\
\hline 1 & $\begin{array}{l}\text { Minimum data rate (Kbps) - } \\
\text { "video/audio + video/text" }\end{array}$ & $19 / 2 / 4$ \\
\hline 2 & $\begin{array}{l}\text { Maximum data rate (Mbps) } \\
3\end{array}$ & $\begin{array}{l}\text { Channel error probability } \\
\text { not more than 5-8\% } \\
\text { (without special coding) }\end{array}$ \\
\hline 4 & Channel delays (recommended) & not more than 1 sec. \\
\hline 5 & $\begin{array}{l}\text { IP Packet Delivery Timeout } \\
\text { (Recommended) }\end{array}$ & not more than 100 msec. \\
\hline 6 & $\begin{array}{l}\text { Channel Signal Fluctuations } \\
\text { (Recommended) }\end{array}$ & not more than 10\% (preferably) \\
\hline
\end{tabular}

We will note that the price range for modern VCS is very wide - from 500 to 2500 dollars for the Desktop System for work in a local area network, and from 5000 to 50000 dollars for the Videoconference Room System, operating both in local and and in external networks. The choice of a particular VCS is determined by the company's business objectives and capabilities. 


\subsection{Office automation and document management systems}

Office Automation Systems is based on office automation and records management automation programs that cover all types of office-related issues that need to be studied and accepted and require approval from the hierarchy of managers ${ }^{1}$.

Modern document management systems have advanced means of creating and sending documents in an automated manner, allowing you to track the routes and correctness of filling the document at all stages of its creation or processing.

In today's market are presented dozens of available software products of domestic and foreign companies in a wide price range, on the Internet you can find different versions of Open Source products for office management.

\subsection{Group Activity Planning}

The task of Group Activity Planning systems is to simplify the agenda planning process of working groups, their daily, weekly and long-term activities. By working with a shared database and scheduler, an organization can minimize overlays in team members' schedules. Such Outlook modules are now embedded in virtually all office applications, and MS Project and Primavera software packages are used for quick planning and reliable execution control.

\subsection{Collective design of textual documentation and graphic materials}

Group documentation development is the creation of a set of documentation at a time by a group of employees, some of whom can work together on a single document (identifying and formulating requirements, developing specifications, drawing up a plan, report, instructions, preparing the text of a brochure or article).

Using a system for collecting documentation collectively allows each member of the workgroup to create and edit their own sections of documents, which may include text, graphics, spreadsheets etc. The hardware for this system includes a file server with databases, which is one of the nodes on the LAN and with which the workgroup personal computers are connected.

\footnotetext{
1 Мирошник И.В. Теория автоматического управления. Линейные системы. Санкт-Питербург,
} $2005.336 \mathrm{c}$. 
It focuses on all group documentation, text editors, and graphics packages (if the interaction is built on a client-server scheme).

For the group to create documents together, specialized software is used to identify, locate, track, move and maintain documents, and configure and control complex multi-page documents containing text, tables, and graphs.

\subsection{Text Database Systems for Open Working Groups}

The use of such databases (DBs) is a very effective way of accessing unstructured textual data that stores a variety of organization materials - a body of textual data obtained from emails, electronic message boards and collective free access resources. It is an important corporate resource that can be used to solve internal tasks, work with clients and in many other cases $^{2}$.

When storing text data, an effective way to systematize large amounts of information is to use link technology and hypertext. Using hypertext provides users with quick and convenient access to information contained in large documents. Hypertext sharing allows people to conduct a distributed work session in real time, for example, simultaneously viewing and editing different sections of text. User actions are immediately displayed on the displays of all participants who have opted for the highcoupling interaction mode.

If the user chooses the weak-link interaction mode, he or she may take some actions that will not be immediately visible to others, but the Source Safe System will always capture and save any changes made.

Note that in the 80s and 90s of the XX century, the leader among Lotus Notes / Domino Lotus products was a leader among low-cost software products that implement open source teamwork on the organization's LAN. This product has many important features.

Lotus Notes databases store documents containing graphical data, spreadsheets, text information, etc. in the form of a single entry. What's more, this software is compatible with many popular text editors, spreadsheet applications, and graphics packages for the PC.

Lotus Notes can work with different operating systems and with different hardware. It can be used on any computer running Windows or

\footnotetext{
${ }^{2}$ Цыпкин Я.З. Основы теории автоматических систем. Главная редакция физико-математической литературы изд-ва «Наука», Москва, 1977, 56 с.
} 
Unix, as well as some popular network operating systems, including Novell, Banyan, and IBM. This interoperability simplifies the process of sharing information and user collaboration across large distributed systems.

\subsection{Database management systems for workgroups}

Placing, storing, securing and issuing information on request are fundamental functions of automated IS. Data storage is performed on secondary storage devices, using a hierarchical system of data levels: bits, bytes, fields, records, files and databases. Each record in the database contains specific fields of a given length, the record set is a file.

Data Base Management System - DBMS provides the user with the necessary data, hiding technologies for their placement, storage and maintenance ${ }^{3}$.

Workgroup DBMS is software for managing (entering, updating, organizing, querying, reporting, etc.) databases. Such popular databases as Microsoft Access, Progress, MySQL can be used by one person and a group of executors. The difference between DBMS for workgroups and individual DBMS is that DBMS for workgroups control access and sharing of data and ensure their integrity in teamwork.

Modern DBMS, implemented, for example, technologies and tools Microsoft and Oracle, provide many flexible functions for teamwork with complex and distributed databases. Note that products such as Apache Web servers, MySQL databases, or PostreSQL are currently available.

\subsection{Support systems for preparation and decision making}

Since the mid-1980s, when the focus of IP began to shift from reporting to the use of IP to support business implementation, systems were being developed and increasingly used to enable teams of professionals to effectively prepare for business decision-making. Such a teamwork system is an "interactive automated system" that facilitates decision-making on unstructured issues by the team members of Decision Support Systems.

In the early 1990s, there was a generalized system of requirements for technological support of such groups and the necessary communications. Each member of such a group has a personal computer or workstation that

\footnotetext{
${ }^{3}$ Попович М.Г., Ковальчук О.В. Теорія автоматичного керування: підручник. 2-ге вид., переробл. і допов. Київ.: Либідь, 2007. 656 с.
} 
is connected on a local or Internet network to the computers of the other members of the group, as well as to one or more large screens or electronic boards for each participant groups could see information entered by others.

Software for group decision-making systems should support specialized functions such as anonymous input of ideas and user comments, list of user input, voting, ranking of alternative solutions and their display (Dialog Mapping System).

The human component includes either several experts, analysts, representatives of interested project teams, and a moderator who conducts the session and mediates between the group and the computer system. The group's tasks include establishing personal communications, discussing and systematically analyzing problems, resolving emerging issues, negotiating, resolving conflicts, designing solutions, preparing documents, and sharing them.

Based on the application of IT Integrated Collaborative Environments ICE, which includes audio and video equipment, procedures, techniques, aids and data required for the work, provides support for group meetings, which can be distributed over time and in space.

Shared software is incorporating an increasing number of Internet protocols. Such products include, for example, Lotus Development's Domino or Microsoft Exchange. It is no longer a question of securing certain areas of teamwork.

There are many products on the market from leading foreign software manufacturers Microsoft, IBM, Intel, Sun Microsystems, Borland, Novell, some domestic companies that implement a full-featured environment (IT infrastructure) to manage the company's activities and effective IT support of these activities to solve the major business tasks

\section{IT based on the concept of artificial intelligence}

What is the difference between Crisp Logic and Fuzzy Logic? In Crisp Logic, the expected consequence always unambiguously follows the stated reference, if clear rules of the condition are fulfilled - for example, "if A, then B", or, "if A and B, then C". When the Fuzzy Logic, the boundaries of the condition are not defined or clearly defined: "if $A$, then in the time interval [T1, T2] B may be much greater than B, and may be almost equal to B" - it all depends on the initial and current conditions, which can change rapidly even within a fixed period of time [T1, T2]. 
Algorithms for analyzing such situations, as a rule, implement scenario scenarios for the risk assessment of each variant. Accordingly, the information system in this case, in addition to the standard functions of data collection, storage and transmission, should contain modules that implement the processing and multivariate analysis of information. Since the development of a business situation can be determined by several parameters, and models describing such situations are rarely linear, the real problem is often reduced to the tasks of multivariate estimation and nonlinear optimization ${ }^{4}$.

In this context, Decision Support System (DSS), Expert Information System (EIS), Executive Support System (ESS), Diagnostic Information System (DIS), Image Recognition System (IRS) and Searching System modules are typically built using the principles that are called "principles of artificial intelligence".

Artificial Intelligence is a section of computer linguistics and informatics that deals with formalizing problems and tasks that resemble human tasks. In most cases, the algorithm for solving the problem is unknown in advance. There is no precise definition of this science, since philosophy does not address the nature and status of human intelligence. There is also no exact criterion for achieving "intelligence" by the computer, although a number of hypotheses, such as the Turing test or the Newell-Simon hypothesis, have been proposed before artificial intelligence. There are now many approaches to understanding the tasks of artificial intelligence and to creating intelligent systems.

In addition, artificial intelligence can be defined as "a set of theoretical methods and physical computing devices whose task is to reproduce reasonable considerations and actions aimed at achieving the expected or new result".

One of the classifications identifies two approaches to the development of artificial intelligence: descending, semiotic - the creation of symbolic systems that model high-level mental processes: thinking, judgment, language, emotions, creativity, etc.; ascending, biological - the study of artificial neural networks and evolutionary computations that model intellectual behavior on the basis of smaller "non-intellectual" elements.

\footnotetext{
${ }^{4}$ Иващенко Н.Н. Автоматическое регулирование. Теория и элементы систем. Учебн. для вузов. Изд. 4-е, перераб. и доп. Москва: «Машиностроение», 1978. 236 с.
} 
This science is related to psychology, neurophysiology, transhumanism and others. Like all computer science, it uses a mathematical apparatus. Of particular importance to her are philosophy and robotics.

Artificial intelligence is a very young field of research, started in 1956. Its historical path is reminiscent of a sine wave, each "take-off" of which was initiated by some new idea. In the 1950s, Wiener, Newell, Simon, and Shaw appeared, exploring the essence of different tasks. The results are algorithms and computer programs "Theoretical Logic", designed to prove theorems in numerous statements, and "General Problem Solver". These works initiated the first stage of research in the field of artificial intelligence related to the development of algorithms and programs for solving problems based on the use of various heuristic methods.

Unlike algorithmic methods that allow for formal verification of correctness, heuristic methods of solving the problem are considered as inherent in human thinking in general, which is characterized by the emergence of intuitive assumptions about the way to solve the problem.

Thus, the overall task of using artificial intelligence is to build a computer-based intellectual system that would have a level of effectiveness in solving informal tasks that is comparable to human or superior. As a high-level criterion for the intelligence of systems based on artificial intelligence technology, an imaginary experiment known as the "Turing test" proposed by Alan Turing in 1950 was proposed. in the article "Computers and Mind" to see if a computer is "intelligent" in the human sense of the word.

Today, the position on the sine wave is on the decline, inferior to the application of already achieved results in other fields of science, industry, business and even in everyday life.

Although far-reaching artificial intelligence is far, some progress has been made in the formation of so-called expert systems and neural networks.

Modern expert systems use the knowledge and intuition of experts people who are deeply versed in solving a range of tasks (specialists in this subject area). Expert systems are a computing structure that independently generates an algorithm for solving a possible set of logic subsystems and computational operations designed by experts. The choice of certain 
subsystems of operators is made according to the estimates and comparisons formulated earlier by experts.

Neural networks are also interesting. Previously, it was called the neural network "perseptio", because the main task in their formation was pattern recognition.

Neural networks use non-linear mathematical models of neurons as elements, of which there may be many in the network. Most neurons can be tuned by changing their response to the input signal. If there are a sufficient number of tasks in the required and broad class of tasks whose solution is known in advance, you can start learning a neural network - a neurocomputer. The network is set up - trained, passing through it all the known decisions and seeking the necessary answers on the way out. The setting is to select the parameters of the neurons. Once set up, the network is able to correctly answer questions from the same series of tasks.

It is not without reason that mathematicians believe that the mechanism for solving problems in expert systems and neural networks is almost similar. But if, in the case of a neural network, even its adjuster does not understand how knowledge (ie, the network is a so-called "black box") is formed in its structure, then its creators must put that knowledge into the expert system. some form (using a certain formalism). Usually, when working with an expert system, it creates new knowledge, which it then uses. By the way, you can always review this knowledge of the expert system and check the solution of each problem at all its stages. But the problem is hidden in the obvious shortcomings of formalism, invented by man, the very structure of the representation of knowledge, which may simply not meet the required level of description of real tasks. The neural network does not use formalisms and largely behaves like natural intelligence.

There is no single answer to what artificial intelligence (AI) deals with. Almost every author who writes a book on artificial intelligence is repelled by any definition, considering in his light the achievements of this science. Usually, these definitions are as follows: Artificial intelligence studies methods of solving problems that require human understanding. Roughly speaking, this is about teaching AI to solve intelligence tests. This involves developing ways to solve problems by analogy, methods of deduction and induction, the accumulation of basic knowledge and the ability to use them; artificial intelligence studies methods of solving problems for which there are no ways of solving or which are not correct (due to limitations in time, memory, etc.). Due to this definition, intellectual algorithms are often used to 
solve NP-complete tasks, such as traveling salesman tasks; artificial intelligence is involved in modeling the human higher nervous activity; Artificial intelligence is systems that can operate with knowledge, and most importantly, learn. First of all, it is about recognizing the class of expert systems (the name comes from the fact that they are capable of replacing expert people) with intellectual systems.

It follows that the scientific aspect of the problem of artificial intelligence concerns attempts to explain its work and explores the possibility of constructing common algorithms for its functioning. An applied aspect of AI involves the computer solution of a variety of problems that do not have a clear algorithmic solution, or multivariate "What if" tasks, that is, tasks with fuzzy goals and fuzzy logic. It uses "human" ways to solve such problems, that is, to simulate the situation when such a problem is solved by a person.

The latter approach, which began to develop since the 1990s, is called the agent-oriented approach. This approach focuses on the methods and algorithms that will help the intelligent agent to survive in the environment while performing their task. Therefore, search and decision algorithms are much more often studied here.

The fields of application of artificial intelligence methods are extremely wide: the proofs of informal theorems and the solution of problems with fuzzy logic; game theory, study of game situations and possibilities of synthesis of decisions (theory and practice of computer chess); recognition of images (symbols, texts, language, images) for the purpose of search, processing and adaptation; adaptive programming; imitation of creative activity - a work of literary texts, poems, music; data processing and transformation in natural languages, machine translation; machine vision, virtual reality building; learning systems based on neural networks; control systems and robotics (automotive, aviation, aerospace, humanoid multifunctional works, etc.); building specialized information systems to support business decision-making.

\subsection{Data mining systems}

A class of technologies and systems created on the basis of artificial intelligence principles and intended to support business decision-making under uncertainty, became widely used in business and was called "Business Intelligence (BI)". 
For the first time, the term "Business Intelligence" was introduced by Gartner analysts in the late 1980s as "a central user process that includes access to information and its exploration, analysis, intuition and understanding that lead to improved and informal decision making" .

Later, in 1996, refinements were made - tools for analyzing data, building reports and queries that could help business users overcome the complexities of processing, interpreting and presenting data in order to synthesize meaningful information from them. These tools collectively fall into a category called Business Intelligence Toolware.

Today, BI product categories include: BI tools and BI applications. BI tools can be divided into the following types: Query / ReportGenerator (QRG); advanced BI tools - first of all, Online Analytical

Processing - OLAP; Enterprise BISuites - EBIS of various configurations built into ERP systems; BI platform.

Multidimensional OLAP servers, as well as relational OLAP mechanisms, are BI tools and infrastructure for BI platforms, on the basis of which various applications with "custom" interfaces are being developed. These tools are used to access data, multidimensional and multivariate analysis, and generate reports based on data that is most often housed in various storefronts, warehouses, databases, or data warehouses. Executive Support System (ES) is as an example of BI-application. BI applications are usually focused on specific important functions of the organization, such as analysis of market trends, risk analysis, analysis and forecasting of sales, budget planning, etc. They can be used more widely to build a Balanced Scorecard System or Enterprise Perfomance Management. Methods and systems of data mining, built on the basis of neural self-learning networks, are widely used in the creation of modern information systems. This is a large class of systems whose architecture has some analogy to the construction of neural tissue from neurons.

In one of the most common architectures - the multilayer perceptron with reverse error propagation - it simulates the work of neurons in the hierarchical network, where each higher-level neuron is connected by its inputs to the outputs of the layer below the neurons.

The neurons of the lowest layer are given the values of the input parameters, on the basis of which it is necessary to make some decisions, predict the development of the situation, etc. These values are regarded as signals transmitted to the next layer, weakening or amplifying depending 
on the numerical values (weights) attributed to the inter-neural relationships. As a result, the output of the neuron of the upper layer produces some value, which is considered as the response-response of the entire network to the input values of the input parameters. In order for the network to continue to be used, it must first be "trained" on previously obtained data, for which both the values of the input parameters and the correct answers are known. "Training" is the selection of weights of interneural connections, which provide the closest closeness of network responses to the known correct answers.

There is a scheme of "intelligent self-learning subsystem" that can be used as part of expert, diagnostic, retrieval and other such systems. The work program "launches" a set of initial data, boundary conditions and approximate exit conditions from the iterative chain. These options are related to sets of known situations and known solutions.

The neural network analyzes the data, identifies the correlations, and then selects the sets of the most likely solutions. This set forms the initial model. The parameters are further varied and new data and rules added. When a set of probable values does not improve the model, the condition for issuing a final prediction is triggered. Recently, evolutionary algorithms are actively developing, which involve the creation of a population of programs, their training, mutations, crossing (exchange of parts of programs) and testing for the fulfillment of a target task.

The programs that work best survive - and after many generations, the most effective program comes out. Very effective methods of creating intelligent search and information systems using Multi Agent System, which operate in the information space, interpreting the task, depending on the conditions and search results. Agent means a software or hardware entity capable of acting in the interest of achieving the goals set by the user. An agent's level of intelligence can be assessed as his ability to use the "old" and build "new" knowledge to accomplish the task in previously unknown situations and problem areas where the evaluated agent is used as an active problem solver. 


\section{REFERENCES}

1. Мирошник И.В. Теория автоматического управления. Линейные системы. Санкт-Питербург, 2005. 336 с.

2. Цыпкин Я.3. Основы теории автоматических систем. Главная редакция физико-математической литературы изд-ва «Наука», Москва, 1977, 56 с.

3. Попович М.Г., Ковальчук О.В. Теорія автоматичного керування: підручник. 2-ге вид., переробл. і допов. Київ: Либідь, $2007.656 \mathrm{c}$.

4. Иващенко Н.Н. Автоматическое регулирование. Теория и элементы систем. Учебн. для вузов. Изд. 4-е, перераб. и доп. Москва: «Машиностроение», 1978. 236 с.

\section{Information about the author:} Kyselov V. B.

Doctor of Technical Sciences, Professor, Director of the Institute of Municipal Administration and Urban Economics of the V. I. Vernadsky Taurida National University 